\title{
Prevalence of idiopathic fecal incontinence in a community-based sample
}

\author{
Alexandra Ilnyckyj MD FRCPC
}

A Ilnyckyj. Prevalence of idiopathic fecal incontinence in a community-based sample. Can J Gastroenterol 2010;24(4):251254.

BACKGROUND: The epidemiology of fecal incontinence (FI) remains incompletely understood. The use of different interview questions in highly selected populations has resulted in widely varying reported rates. AIM: To define the prevalence of idiopathic FI in a Canadian urban community sample using a validated interview questionnaire.

METHODS: Respondents completed a telephone interview regarding bowel health as part of the 2006 Winnipeg Area Study (WAS). The WAS has been conducted annually by the Department of Sociology at the University of Manitoba (Winnipeg, Manitoba) since 1981. The household was the primary sampling unit. An eligible respondent was an individual 18 years of age or older who lived at that address, matched a randomly preassigned sex and provided consent. Respondents were asked whether they had ever been diagnosed by a physician with colon cancer, ulcerative colitis, Crohn's disease or irritable bowel syndrome. They were also asked, 'In the past 12 months have you experienced accidental leakage of liquid or solid stool?' Respondents were asked not to consider short-term diarrheal illness. Finally, respondents were asked to rank eight attributes of bowel habit on a 10-point scale. Answers ranking 5 points or greater were defined as having the attribute.

RESULTS: In the city of Winnipeg, population 650,000, 1153 households were contacted. Of these, $727(63 \%)$ agreed to participate and formed the study sample. Of the respondents, 361 were men and 366 were women (mean age 47 years). The sociodemographics of these respondents were comparable with those reported in previous WAS samples and the 2001 Canadian census data. Respondent cooperation, high interview quality and willingness for repeat contact were rated by the interviewers at $93 \%, 89 \%$ and $90 \%$, respectively. FI was reported by $3.7 \%$ of the sample. There was no difference in sex or age of those reporting FI when compared with the rest of the sample. With physiciandiagnosed gastrointestinal conditions removed from the analysis, $2.0 \%$ of the sample reported FI. Of the gastrointestinal conditions, only irritable bowel syndrome demonstrated a significant correlation with FI (one-sided $\chi^{2}$ test 11.567, degrees of freedom $=1 ; \mathrm{P}=0.001$ ). Four bowel habit attributes demonstrated strong correlation with FI ( $\mathrm{P}=0.0001$ for each $t$ test): admission to any type of bowel accident, inability to delay toileting, inability to control passage of stool and need to wear a pad due to soiling. These four bowel habit attributes were reported (ranked 5 points or greater) by $1.5 \%, 22 \%, 2.4 \%$ and $1.5 \%$ of the sample, respectively.

CONCLUSION: The prevalence of idiopathic FI in a well-defined community sample was $2.0 \%$. There was no sex preference and the mean age of affected individuals was 47 years - demographic variables that did not vary among the sample. These findings suggest the need to develop a new paradigm beyond aging and childbirth injury to study the pathophysiology of FI. It is imperative to control for subjects with known irritable bowel syndrome in epidemiological studies because their inclusion in the present analysis doubled the calculated prevalence of FI.

Key Words: Epidemiology; Fecal incontinence

\section{La prévalence de l'incontinence fécale idiopathique dans un échantillon communautaire}

HISTORIQUE : L'épidémiologie de l'incontinence fécale (IF) demeure mal comprise. Le recours à diverses questions d'entrevue dans des populations hautement sélectionnées a donné lieu à des taux de déclaration très variés. OBJECTIF : Définir la prévalence d'IF idiopathique dans un échantillon communautaire en milieu urbain au moyen de questions d'entrevue validées.

MÉTHODOLOGIE : Les répondants ont participé à une entrevue téléphonique au sujet de la santé intestinale, dans le cadre de l'étude sur la région de Winnipeg (WAS) de 2006. Le département de sociologie de l'université du Manitoba (Winnipeg, Manitoba) a effectué les WAS tous les ans depuis 1981. Le ménage était l'unité d'échantillonnage primaire. Un répondant admissible était une personne de 18 ans ou plus qui habitait à cette adresse, était d'un sexe prédéfini et accordait son autorisation. On demandait aux répondants s'ils avaient déjà reçu un diagnostic de cancer du côlon, de colite ulcéreuse, de maladie de Crohn ou de syndrome du côlon irritable par un médecin. On leur posait également la question suivante : «Dans les 12 derniers mois, avez-vous subi une perte accidentelle de selle liquide ou solide? » Les répondants étaient invités à ne pas tenir compte d'une maladie diarrhéique à court terme. Enfin, on leur demandait de classer huit caractéristiques d'habitudes intestinales sur une échelle de dix points. Les réponses dont la note correspondait à cinq ou plus étaient définies comme dotées de la caractéristique.

RÉSULTATS : Dans la ville de Winnipeg, où la population est de 650000 habitants, on a pris contact avec 1153 maisonnées. De ce nombre, 727 (63\%) ont accepté de participer et ont formé l'échantillon à l'étude. Parmi les répondants, 361 étaient des hommes et 366, des femmes (âge moyen de 47 ans). Leurs caractéristiques sociodémographiques étaient comparables à celles constatées dans un échantillon antérieur de la WAS et dans les résultats du recensement canadien de 2001. Les intervieweurs ont accordé les pourcentages respectifs de $93 \%, 89 \%$ et $90 \%$ à la collaboration des répondants, à la haute qualité des entrevues et à la volonté de reprendre contact. L'IF était déclarée par 2,7 \% de l'échantillon. On ne constatait aucune différence selon le sexe ou l'âge des personnes faisant état d'une IF par rapport au reste de l'échantillon. Lorsqu'on retirait les maladies diagnostiquées par un médecin de l'analyse, 2,0 \% de l'échantillon déclaraient une IF. Parmi les maladies gastro-intestinales, seul le syndrome du côlon irritable présentait une corrélation significative avec l'IF (test unilatéral $\chi^{2} 11,567$, degrés de liberté=1; $P=0,001$ ). Quatre caractéristiques d'habitudes intestinales indiquaient une forte corrélation avec l'IF ( $\mathrm{P}=0,0001$ par test $t$ ) : l'admission de tout type d'accident intestinal, l'incapacité de retarder l'élimination, l'incapacité de contrôler le passage des selles et la nécessité de porter une serviette hygiénique pour éviter de se souiller. Ainsi, $1,5 \%, 22 \%, 2,4 \%$ et $1,5 \%$ de l'échantillon ont respectivement déclaré ces caractéristiques d'habitudes intestinales (ayant reçu cinq points ou plus). CONCLUSION : La prévalence d'IF idiopathique dans un échantillon bien défini de la collectivité s'élevait à 2,0\%. On ne remarquait pas de préférence selon le sexe, et les personnes touchées avaient un âge moyen de 47 ans. Ces variables démographiques ne changeaient pas dans l'échantillon. Ces observations indiquent la nécessité de mettre au point un nouveau paradigme en plus du vieillissement et des traumatismes de l'accouchement pour étudier la physiopathologie de l'IF. Il est impératif de vérifier la présence de sujets ayant un syndrome du côlon irritable connu dans le cadre des études épidémiologiques, car leur intégration à la présente analyse doublait la prévalence calculée d'IF. 
$F_{\text {end }}^{\text {end }}$ ecal incontinence $(\mathrm{FI})$ - the involuntary loss of solid or liquid stool causing social or hygienic problems - is a disabling chronic condition. It has long been recognized as a problem, particularly in nursing home populations (1). However, there is growing awareness that FI may be a significant problem within community populations (2-4).

The epidemiology of FI is not fully understood (5-13). Some studies introduce bias by only including older subjects $(5,6)$ and/or limiting their study to women $(7,8)$. This practice is based on the hypothesis that FI is secondary to childbirth injury and/or aging of the pelvic floor. Although these population subsets are at unique risk, FI is not limited to them. The literature generally supports the increased risk of FI associated with aging (2). Importantly, contemporary studies demonstrate no sex preference (9-11).

The estimate of FI in community populations is variably reported, ranging from $0.5 \%$ to $10 \%(2-13)$. This varying prevalence relates to the lack of validated measures, differing populations and study methodology.

A clear understanding of epidemiology is required to assist in planning of health care provisions for the community (2). As well, defining the epidemiology is imperative if we are to advance our understanding of the pathogenesis of FI.

The aim of the present study was to identify a community sample and use a validated survey question to define the prevalence of idiopathic FI.

\section{METHODS}

The Department of Sociology at the University of Manitoba (Winnipeg, Manitoba) conducts a yearly research project - the Winnipeg Area Study (WAS) (14). It consists of administering a composite questionnaire containing sociodemographic and quality of life questions as well as sets of substantive questions from different contributing researchers. The 2006 WAS represented the 23rd study by the Department and the substantive questions included the topic of bowel health and incontinence.

\section{Sampling design}

The sample population for the study was designated as all working telephone numbers in the City of Winnipeg. A random sample of telephone numbers was generated for telephone interviewing using a computer-based model. The household was the primary sampling unit. Age, residence in the household and sex were the selection criteria to choose a respondent within each of the households. An eligible respondent was 18 years of age or older, resided at the address and fulfilled a random preassignment of sex.

\section{Interview}

Ten professional interviewers were used, and all had previous experience with the WAS. All interviewers underwent training sessions and instruction to review the study protocol in preparation for the 2006 study. Interviewers signed a confidentiality and nondisclosure agreement. They informed all respondents that information obtained during the interview was anonymous and confidential. All residential numbers were contacted by the interviewer 10 times before being considered a 'noncontact'.

\section{Survey}

Respondents were asked whether they had ever been diagnosed by a physician with colon cancer, ulcerative colitis, Crohn's disease or irritable bowel syndrome (IBS). A single validated question developed for self-reporting FI was asked $(4,8,15)$. Finally, respondents were asked to rank eight attributes of bowel habit (16) on a 10-point scale, with never or infrequently anchored at 1 and always or frequently anchored at 10 . Answers ranking 5 points or greater were defined as having the attribute.

The study was approved by the Psychology and Sociology Research Ethics Board of the University of Manitoba.

\section{RESULTS}

Winnipeg is a midwestern city in the province of Manitoba, with a population of 650,000 . In this population, 1153 households were contacted and, of these, 727 (63\%) agreed to participate and formed the study sample. The sample was comprised of 361 men and 366 women, with a mean age of 47 years. The sociodemographics of the respondents were comparable with those reported in previous WAS samples and, moreover, with the 2001 Canadian census data - a national, law-mandated census (Table 1).

Respondent cooperation, high interview quality and willingness for recontact were rated by the interviewers at $93 \%$, $89 \%$ and $90 \%$, respectively.

FI was reported by $3.7 \%$ of the sample. There was no sex or age difference between respondents reporting FI compared with the remainder of the sample. With data reporting physiciandiagnosed gastrointestinal conditions removed from the analysis, $2 \%$ of the sample reported FI (Table 2). Of the gastrointestinal conditions, only the incidence of IBS demonstrated a significant relationship with FI $\left(\chi^{2}=11.567\right.$, degrees of freedom $=1$; $\mathrm{P}=0.0001)$.

Four bowel attributes were significantly related to the presence or absence of FI at $\mathrm{P}=0.0001$ (independent groups $t$ test). Respondents who reported the presence of FI had more accidents (question 5), an inability to delay toileting (question 8), an inability to control passage of a bowel movement (question 9) and the need to wear a pad due to fear of soiling (question 10) (Appendix). These four bowel attributes were reported and ranked 5 or greater by $1.5 \%, 22 \%, 2.4 \%$ and $1.5 \%$ of the sample, respectively.

\section{DISCUSSION}

Increasingly, there is recognition that FI is an important community health care issue. Changing population demographics and high expectations for quality of life are cited as contributing to this awareness $(2-4)$.

There is tremendous variability in the reported rates of FI in community samples, ranging from $0.5 \%$ to $10 \%$. This variability relates to the population sampled, measures used and study methodology. In the present study, we were able to define a community sample representative of the Canadian urban population and obtain a high response rate. As well, we used a validated survey question to determine the presence of FI. Moreover, we controlled for respondents with self-reported gastrointestinal illness aiming to identify the prevalence of idiopathic FI.

Our data demonstrated that FI is common, affecting 3.7\% of a representative sample community population. When we excluded those with known gastrointestinal conditions, the prevalence decreased to $2 \%$. It is possible that some of these participants had incontinence due to diarrhea of unrecognized or undiagnosed inflammatory bowel disease, or IBS. Those with known 
TABLE 1

Comparison of age and sex distribution of the 2001 Winnipeg census data and the Winnipeg Area Study (WAS) sample

\begin{tabular}{lcc}
\hline & 2001 Winnipeg census* & WAS \\
\hline Age, years & & \\
$20-24$ & 9.5 & 8.3 \\
$25-54$ & 60.2 & 58.3 \\
$55-64$ & 11.9 & 15.4 \\
$65-74$ & 9.3 & 10.2 \\
$\geq 75$ & 9.2 & 7.8 \\
Sex & & \\
Men & 47.7 & 49.6 \\
$\quad$ Women & 52.3 & 50.4 \\
Total, n & 498,185 & 722 \\
\hline
\end{tabular}

Data are presented as \% unless indicated otherwise. ${ }^{\star} D a t a$ acquired from Statistics Canada

gastrointestinal conditions and FI should be included when considering the burden of FI. However, group heterogeneity needs to be minimized when exploring mechanisms of FI or planning treatment strategies. Thus, in our view, recognition of this confounder is important.

The mean age of those affected by FI was 47 years. This finding challenges the hypothesis that FI is secondary to an aging and/or weakened pelvic floor. Similarly, finding the prevalence of FI to be equal among men and women forces the pathophysiology of FI to be reconsidered beyond that of childbirth injury of the pudendal nerve and/or anal sphincters. Age and sex remain unique - not exclusive - risk factors for FI.

The prevalence and age/sex distribution of FI determined in the present study are most consistent with those reported by Kalantar et al (11) in an Australian population using similar methodology and measurement. Our findings confirm reports by two other centres that have also demonstrated no sex preference in the prevalence of FI $(9,10)$.

The present study also questioned participants regarding eight bowel attributes, of which four were found to correlate with FI. One attribute, the inability to comfortably delay toileting, was reported by a large proportion of the sample (22\%). The ability to comfortably delay toileting is an intrinsic characteristic of normal physiology and health. This patient subset possibly offers an opportunity to study FI before clinical expression when pathophysiology may yet be discernable. This finding is exploratory and limited by the lack of validation of these bowel attributes.

It has been demonstrated that FI is infrequently reported to family physicians and gastroenterologists (17). Even when patients with FI are being seen in consultation with a gastroenterologist, only one-half will report the complaint to the specialist. Our findings support the belief that physicians should routinely inquire regarding bowel continence regardless of age, sex, or the presence or absence of an underlying gastrointestinal condition.

\section{CONCLUSION}

The robust sampling methodology and validated measurement tools used in the present study provided reliable data regarding the prevalence of idiopathic FI in a North American population. It conclusively demonstrates that FI affects men and women equally, and is not limited to the elderly. Thus, new
TABLE 2

Prevalence of fecal incontinence (FI) and demographic features $(n=727)$

\begin{tabular}{lccc}
\hline & FI, n (\%) & Male sex, \% & Mean age, years \\
\hline Total sample & $27(3.7)$ & 50 & 47 \\
$\begin{array}{l}\text { Gastrointestinal conditions } \\
\text { excluded }\end{array}$ & $14(2)$ & 50 & 47 \\
\hline
\end{tabular}

paradigms for exploring the pathophysiology of FI need to be considered. Given the encouraging outcomes of sacral nerve stimulators in treating FI, potential mechanisms of injury to sacral nerve reflexes such as direct trauma or infection should be explored as potential causes of FI.

\section{APPENDIX}

The following questions pertain to bowel health. Although not commonly discussed, bowel health problems are important to recognize because they can interfere with daily living. These questions regarding bowel function will help to understand who experiences these difficulties to better target treatment.

1. Have you ever been diagnosed by a physician as having any of the following conditions?

$\begin{array}{lll}\text { Colon cancer } & \text { YES } & \text { NO } \\ \text { Ulcerative colitis } & \text { YES } & \text { NO } \\ \text { Crohn's disease } & \text { YES } & \text { NO } \\ \text { Irritable bowel syndrome } & \text { YES } & \text { NO }\end{array}$

2. In the past 12 months, have you experienced accidental leakage of liquid or solid stool? Do not include problems that occurred as a result of a short-term illness such as the flu or food poisoning.

YES NO

For the remainder of the questions, consider your health over the past year. Again, do not include problems that occurred as a result of a short-term

illness such as the flu or food poisoning.

Choose a number, between 1 and 10 which best reflects your answer to each question. The number "1" indicates that you never or infrequently experience the problem, whereas "10" indicated that you always or frequently experience the problem.

3. I experience abdominal distension or bloating

4. I experience abdominal pain or discomfort associated with altered bowel movements

5. I have had accidents because of an inability to control the passage of a bowel movement until I have reached a toilet

6. After finishing a bowel movement I can be bothered by a sense that I still have more stool left to pass

7. After finishing a bowel movement I can be bothered by the inability to finish wiping myself

8. When I sense the need to have a bowel movement, usually I can comfortably delay using the toilet until a time which is convenient

9. I have experienced an unexpected or embarrassing inability to control my bowel movements

10. I have had to use pads to protect my undergarments due to fear of accidental leakage of stool

\section{REFERENCES}

1. Nelson RL, Furner S, JesudasonV. Fecal incontinence in Wisconsin nursing homes. Dis Colon Rectum 1998:41;1226-9.

2. Landefeld CS, Bowers BJ, Feld AD, et al. National Institute of Health state-of-the-science conference statement: Prevention of fecal and urinary incontinence in adults. Ann Intern Med 2008;148:449-58. 
3. Pretlove SJ, Radley S, Toozs-Hobson, Thompson PJ, Coomarasamy A, Khan KS. Prevalence of anal incontinence according to age and gender: $\mathrm{A}$ systematic review and metaregression analysis. Int Urogynecol J 2006:17;407-17.

4. Bharucha AE, Zinsmeister AR, Locke GR, Schleck C, McKeon K, Melton LJ. Symptoms and quality of life in community women with fecal incontinence. Clin Gastroenterol Hepatol 2006;4:1004-09.

5. Campbell AJ, ReinkenJ, McCosh L. Incontinence in the elderly: Prevalence and prognosis. Age and Aging 1985;14:65-70.

6. Denis P, Bercoff E, Bizien MF, et al. Etude de la prevalence de l'incontinence anale chez l'adulte. Gastroenter Clin Biol 1992;16:344-50.

7. Kok ALM, Voorhorst FJ, Burger CW, van Houten P, Kenemans P, Jansns J. Urinary and faecal incontinence in community residing elderly woman. Age and Aging 1992;21;211-5.

8. Bharucha AE, Zinsmeister AR, Locke GR, et al. Risk factors for fecal incontinence: A population based study in women. Am J Gastroenterol 2006;101:1305-12.

9. Walter S, Hallbrook O, Gotthard R, Bergmark M, Sjodahl R. A population based study on bowel habits in a Swedish community: Prevalence of fecal incontinence and constipation. Scand J Gastroenterol 2002;8:911-16.
10. Perry S, Shaw C, McGrother C, et al; and the Leistershire MRC Incontinence Study Team. Prevalence of fecal incontinence in adults aged 40 or more living in the community. Gut 2002;50:480-4.

11. Kalantar JS, Howell S, Talley NJ. Prevalence of faecal incontinence and associated risk factors. Med J Australia 2002;176:54-7.

12. Drossman DA, Li Z, Andruzzi E, et al. US Householder survey of functional GI disorders: Prevalence, sociodemography and health impact. Dig Dis Sci 1993;38:1569-80.

13. Nelson RL, Norton N, Cautley E, Furner S. Community based prevalence of anal incontinence. JAMA 1995;274:559-62.

14. Lewis TK. Research Report No.69. The 2006 Winnipeg Area Study Sample Report. Winnipeg: Department of Sociology, University of Manitoba, 2007.

15. Bharucha AE, Locke GR, Seide B, et al. A new questionnaire for constipation and fecal incontinence. Aliment Pharmacol Ther 2004;20:355-64.

16. Burgmann T, Martin W, Ilnyckyj A. Fecal incontinence: Focus group methodology to identify best questions and terms. Can J Gastroenterol 2004;(Suppl A):A32. (Abst)

17. Johanson JF, Lafferty J. Epidemiology of fecal incontinence: The silent affliction. Am J Gastroenterol 1996;91:33-6. 


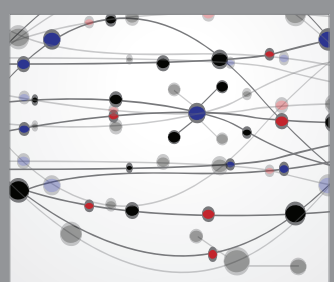

The Scientific World Journal
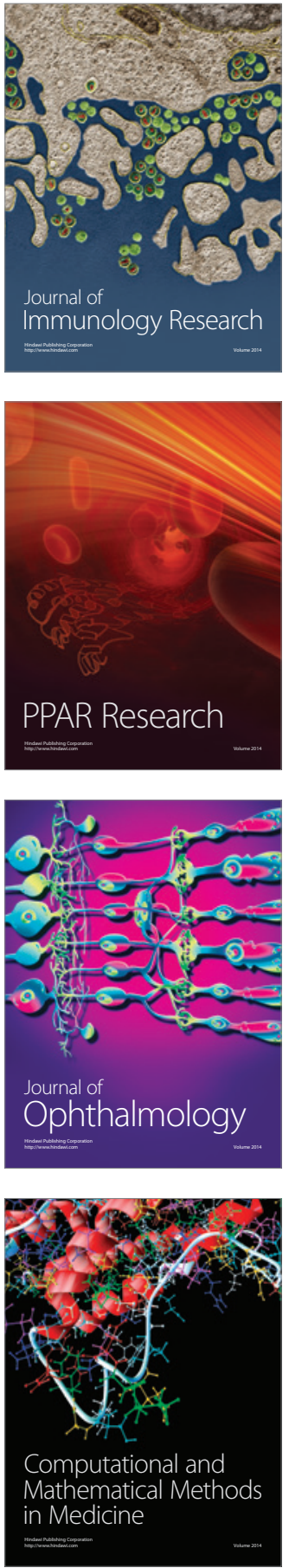

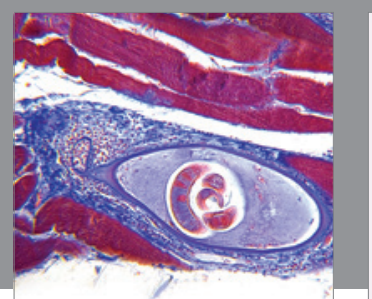

Gastroenterology Research and Practice

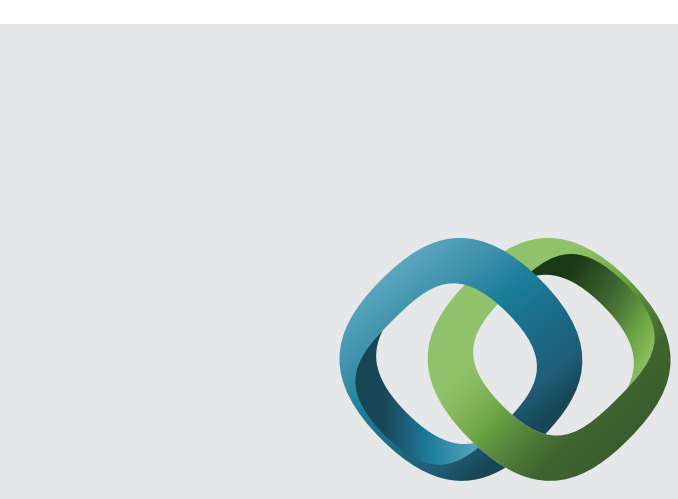

\section{Hindawi}

Submit your manuscripts at

http://www.hindawi.com
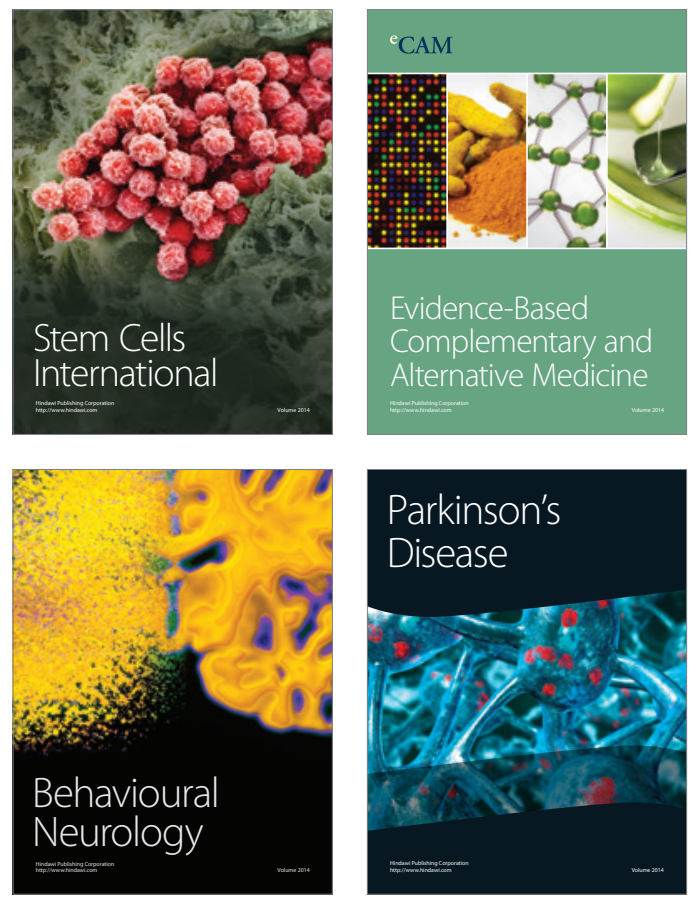
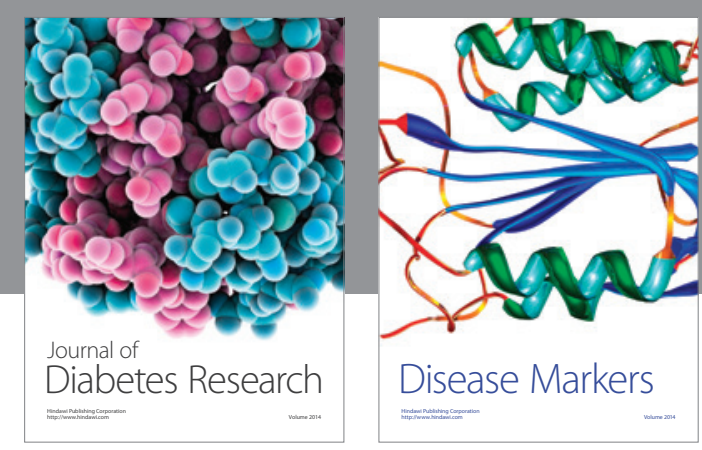

Disease Markers
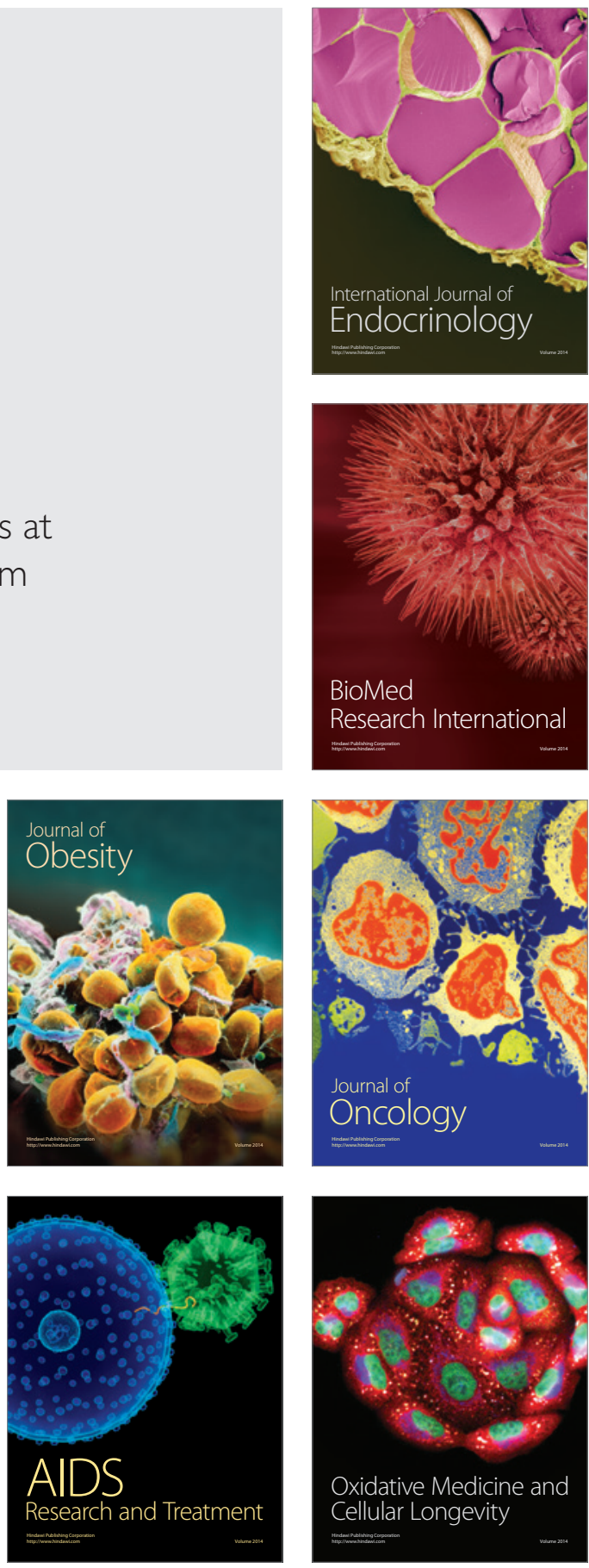